\title{
S6K1 controls pancreatic $\beta$ cell size independently of intrauterine growth restriction
}

Sung Hee Um, ${ }^{1,2}$ Melanie Sticker-Jantscheff, ${ }^{3}$ Gia Cac Chau, ${ }^{2}$ Kristina Vintersten, ${ }^{4}$ Matthias Mueller, ${ }^{5}$ Yann-Gael Gangloff, ${ }^{6}$ Ralf H. Adams, ${ }^{7}$ Jean-Francois Spetz, ${ }^{8}$ Lynda Elghazi, ${ }^{9}$ Paul T. Pfluger, ${ }^{10}$ Mario Pende, ${ }^{11}$ Ernesto Bernal-Mizrachi, ${ }^{9}$ Albert Tauler, ${ }^{12}$ Matthias H. Tschöp, ${ }^{10}$ George Thomas, ${ }^{1,13,14}$ and Sara C. Kozma ${ }^{1,14}$

\begin{abstract}
'Division of Hematology and Oncology, Department of Internal Medicine, University of Cincinnati, Cincinnati, Ohio, USA. ${ }^{2}$ Department of Molecular Cell Biology, Samsung Biomedical Research Institute, Sungkyunkwan University School of Medicine, Suwon, Korea. ${ }^{3}$ Department of Molecular Pathology, Institute of Pathology, University Hospital Basel, Basel, Switzerland.

${ }^{4}$ Lunenfeld-Tanenbaum Research Institute, Mount Sinai Hospital, Toronto, Ontario, Canada. ${ }^{5}$ Novartis Pharma AG, Basel, Switzerland. ${ }^{6}$ Laboratoire de Biologie Moléculaire de la Cellule, CNRS UMR5239, Lyon, France. ${ }^{7}$ Max-Planck-Institute for Molecular Biomedicine, University of Münster, Münster, Germany. ${ }^{8}$ Friedrich Miescher Institute for Biomedical Research, Basel, Switzerland. ${ }^{9}$ Division of Metabolism, Endocrinology and Diabetes, Department of Internal Medicine, University of Michigan, Ann Arbor, Michigan, USA. ${ }^{10} \mathrm{Helmholtz}$ Zentrum München, German Research Center for Environmental Health (GmbH), Institute for Diabetes and Obesity, Garching, Germany. " INSERM, U1151, Université Paris Descartes, Paris, France. ${ }^{12}$ Department of Biochemistry and Molecular Biology, Faculty of Farmacy,
\end{abstract} University of Barcelona, Barcelona, Spain. ${ }^{13}$ Department of Physiological Sciences II, Faculty of Medicine, University of Barcelona, Barcelona, Spain. ${ }^{14}$ Laboratory of Cancer Metabolism, Institut d’Investigació Biomèdica de Bellvitge (IDIBELL), Barcelona, Spain.

Type 2 diabetes mellitus (T2DM) is a worldwide heath problem that is characterized by insulin resistance and the eventual loss of $\beta$ cell function. As recent studies have shown that loss of ribosomal protein (RP) S6 kinase 1 (S6K1) increases systemic insulin sensitivity, S6K1 inhibitors are being pursued as potential agents for improving insulin resistance. Here we found that S6K1 deficiency in mice also leads to decreased $\beta$ cell growth, intrauterine growth restriction (IUGR), and impaired placental development. IUCR is a common complication of human pregnancy that limits the supply of oxygen and nutrients to the developing fetus, leading to diminished embryonic $\beta$ cell growth and the onset of T2DM later in life. However, restoration of placental development and the rescue of IUGR by tetraploid embryo complementation did not restore $\beta$ cell size or insulin levels in S6K1/-- embryos, suggesting that loss of S6K1 leads to an intrinsic $\beta$ cell lesion. Consistent with this hypothesis, reexpression of S6K1 in $\beta$ cells of S6K1/- mice restored embryonic $\beta$ cell size, insulin levels, glucose tolerance, and RPS6 phosphorylation, without rescuing IUGR. Together, these data suggest that a nutrient-mediated reduction in intrinsic $\beta$ cell S6K1 signaling, rather than IUCR, during fetal development may underlie reduced $\beta$ cell growth and eventual development of T2DM later in life.

\section{Introduction}

The common hallmark of frank type 2 diabetes mellitus (T2DM) is insulin resistance, which is initially compensated for by an increase in $\beta$ cell mass and insulin production before eventually yielding to $\beta$ cell failure (1). The number of diabetics worldwide is presently 347 million (2), with WHO projecting that diabetes will be become the 7th leading cause of death by 2030 (3), underscoring the need for novel therapies (4). Ribosomal protein (RP) S6 kinase 1 (S6K1), a downstream effector of the mTOR Complex 1 (mTORC1) signaling pathway (5), has emerged as a potential drug target in the treatment of T2DM (6-8). In earlier studies, we demonstrated that mice deficient for S6K1 are resistant to high-fat diet-induced (HFD-induced) obesity due to increased lipolysis (9) and a lesion in adipogenesis, which we subsequently traced to an impairment in the ability of stem cells to commit to the adipocytic lineage (10). Consistent with a reduction in adiposity, as compared with WT mice, $S 6 \mathrm{~K}^{-/-}$mice maintained on a HFD remain insulin sensitive, despite increased glycemia (9). Increased insulin

Conflict of interest: The authors have declared that no conflict of interest exists. Submitted: May 13, 2014; Accepted: May 6, 2015.

Reference information: J Clin Invest. 2015;125(7):2736-2747. doi:10.1172/JCI77030. sensitivity may also result from the reduced circulating insulin levels in $\mathrm{S} \mathrm{K}^{-1-}$ mice, as well as the loss of a negative feedback loop mediated by S6K1 site-specific phosphorylation to elements of the insulin receptor pathway, particularly insulin receptor substrates $1 / 2$ (IRS1/2) $(5,9)$. In the latter case, phosphorylation of IRS1/2 disrupts its interactions with the insulin receptor and the class 1 PI3K $(11,12)$, which is hypothesized to suppress glucose uptake in muscle and adipose $(5,9)$. Consistent with these findings, liverspecific depletion of S6K1 has been recently shown to protect against HFD-induced hepatic steatosis and systemic whole-body insulin resistance, the latter being associated with reduced insulin levels and loss of the negative feedback loop in muscle and fat (13).

Despite the finding that depletion or loss of S6K1 leads to an increase in insulin sensitivity, there is a concern about the potential efficacy of S6K1 inhibitors for the treatment of T2DM. As noted above, this stems from the fact that S6K1-deficient mice are hypoinsulinemic, a phenotype which we found was not associated with the transcription, synthesis, degradation, or intrinsic secretion of insulin, but with diminished $\beta$ cell size $(9,14)$. It is known that a decrease in $\beta$ cell size has a proportionally larger negative effect on insulin secretion independent of secretory potential (15). Consistent with a role for $\mathrm{S} 6 \mathrm{~K} 1$ in this response, subsequent stud- 

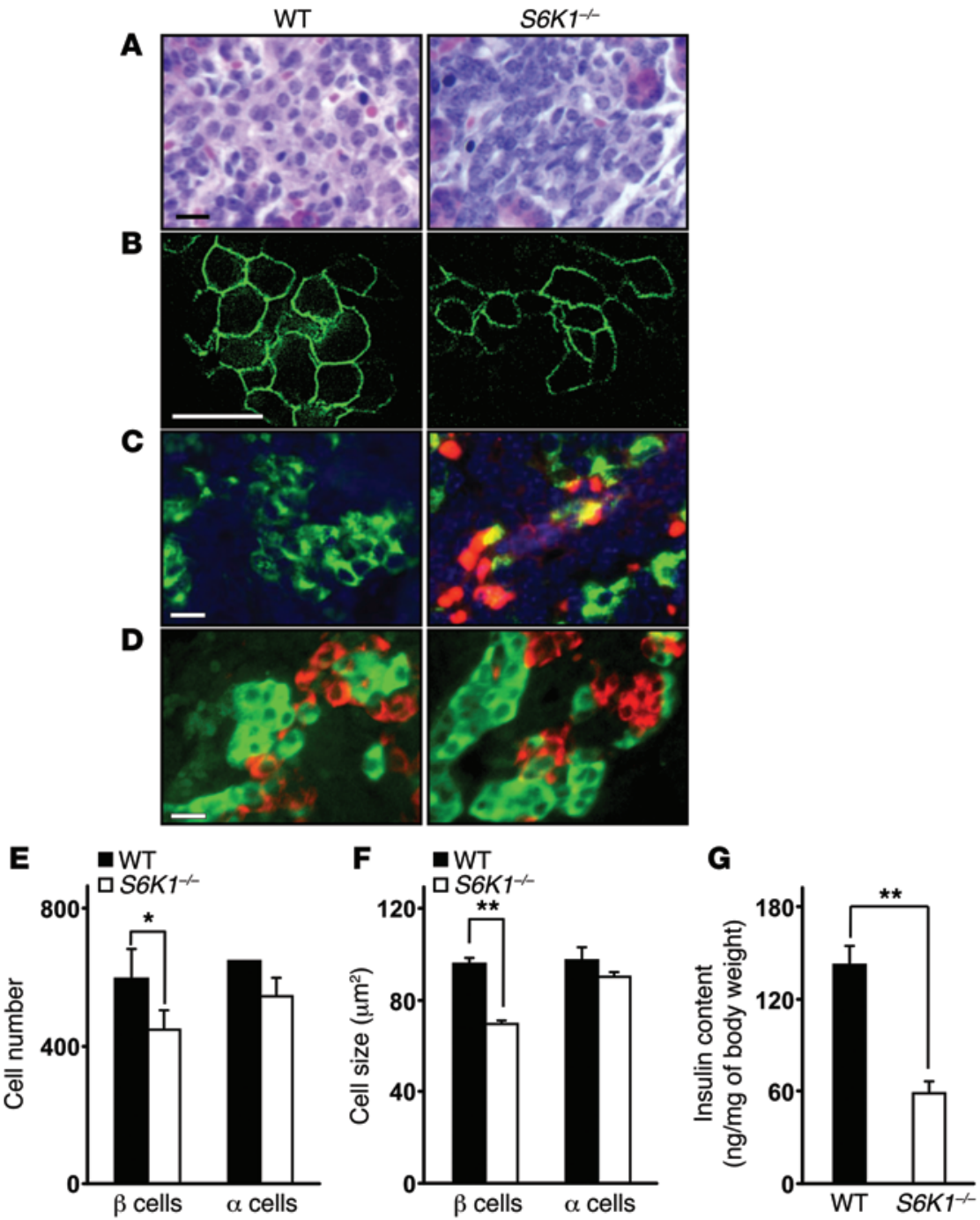

Figure 1. Diminished pancreatic $\beta$ cell size and number in S6K1/- embryos. (A-D) Pancreas sections from WT or S6K1/- embryos at E16.5: (A) histology, by H\&E staining; (B) CLUT2 glucose transporter, by immunofluorescence (IF) staining; (C) cleaved caspase-3 (red), insulin (green) by IF staining and DAPI (blue) staining; and (D) insulin (red) and glucagon (green), by IF staining. (E) $\beta$ cell number in embryonic pancreata ( $n=3$ per genotype). (F) $\beta$ cell size in embryonic pancreata from 45-52 determinations in WT embryos and 29-44 determinations in S6K1/- embryos $(n=3$ per genotype; $\beta$ cell surface: WT, $95.60 \pm 2.69 \mu \mathrm{m}^{2}$; S6K1 $\left.1^{-1-}, 69.54 \pm 1.5 \mu \mathrm{m}^{2}\right)$. (C) Reduced insulin content, normalized for body weight, in embryonic pancreata ( $n=6-9$ per genotype). Scale bars: $25 \mu \mathrm{m}$. In E-G, values are given as mean \pm SEM. ${ }^{*} P<0.05,{ }^{* *} P<0.01 \mathrm{vs}$. WT, unpaired $t$ test. small gestational-age fetuses and newborns (21). The fetal oxygen and nutrient supply is normally actively transported from the mother to the placental trophoblasts, which develop during the early stages of pregnancy and are the first cells of the fertilized egg to differentiate. mTORC1, an upstream kinase required for S6K1 activation, is critical for the trophoblast's development and function (22). Of note, S6K1 activity is markedly reduced in human placentas associated with restricted fetal growth (23). These findings and the observation that acute inhibition of S6K1 by rapamycin in $\beta$ cells has no effect on glucose-stimulated insulin secretion (24) are consistent with IUGR, rather than an intrinsic $\beta$ cell function, being responsible for the reduced body mass, hypoinsulinemia, and the $\beta$ cell size deficit displayed by S6K1 deficient mice at birth $(14,17)$.

Given the importance of S6K1 as a potential therapeutic target in insulin resistance (8) and recent data suggesting that fetal $\beta$ cell impairment, rather than being a consequence, is instead a cause of IUGR (25), we set out to trace the basis of the reduced $\beta$ cell size and hypoinsulinemia observed in adult $S 6 \mathrm{~K}^{-/-}$mice. To address this question, we first determined $\beta$ cell size and insulin content in $S 6 \mathrm{~K}^{-/-}$mouse embryos. Next, we asked which stage of $S 6 \mathrm{~K}^{-/-}$mouse embryonic development was affected and whether the developmental effects could be accounted for by reduced $\beta$ cell size. Finally, employing 2 distinct genetic paradigms, we determined whether the effects on $\beta$ cell size and hypoinsulinemia observed in adult $S 6 \mathrm{~K}^{-1-}$ mice were due to IUGR or were intrinsic to $\beta$ cells.

\section{Results}

$\beta$ Cells from $\mathrm{S} 6 \mathrm{~K}^{-/-}$embryos exhibit reduced cell size and insulin content. As limited intrauterine nutrient availability has been associated with impaired pancreatic $\beta$ cell development (26, $27)$, we asked whether $\beta$ cells are affected in ies showed that targeted $\beta$ cell expression of a constitutively active $S 6 K 1 \mathrm{cDNA}$ leads to an increase in both $\beta$ cell size and insulin secretion (16). However, at birth, $S 6 \mathrm{~K}^{-1-}$ mice are also reduced in body size (17), a phenotype that defines intrauterine growth restriction (IUGR). IUGR is a risk factor for T2DM in adult life and is associated with reduced $\beta$ cell function (18). IUGR affects over $5 \%$ of pregnancies, with the number of incidences progressively increasing over the past decade (19). IUGR is largely attributed to an insufficient oxygen and nutrient supply by the placenta, such that developing tissues and organs of the embryo fail to grow to their normal size (20). IUGR fetuses have reduced circulating insulin levels, impaired $\beta$ cell function, and in more severe cases, reduced $\beta$ cell mass (18). The impairment to $\beta$ cell function is thought to be responsible for the increased insulin sensitivity observed in
$S 6 \mathrm{~K}^{-/-}$mice during embryogenesis. Examination of $\mathrm{H} \& \mathrm{E}$-stained pancreata at E16.5 revealed clusters of endocrine cells in the pancreatic interstitium (Figure 1A). In $S 6 \mathrm{~K}^{-/-}$embryos, we observed a higher density of nuclei in the endocrine cell clusters, as compared with WT embryos (Figure 1A). The same $\beta$ cell phenotype was observed in $\mathrm{S}_{6} \mathrm{~K}^{-/-}$mice obtained either from heterozygous or homozygous parental crosses. Analysis of tissue sections of $\beta$ cells, immunostained for the membrane-associated GLUT2 transporter, confirmed that $S 6 \mathrm{~K}^{-/-} \beta$ cells were smaller than those from WT embryos (Figure 1B). Given that S6K1 deficiency affects apoptosis $(28,29)$, we examined apoptotic $\beta$ cells by costaining for cleaved caspase- 3 and insulin, together with DAPI, to observe nuclei. The result revealed significant levels of cleaved caspase-3 staining in

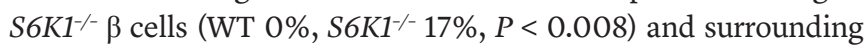


A

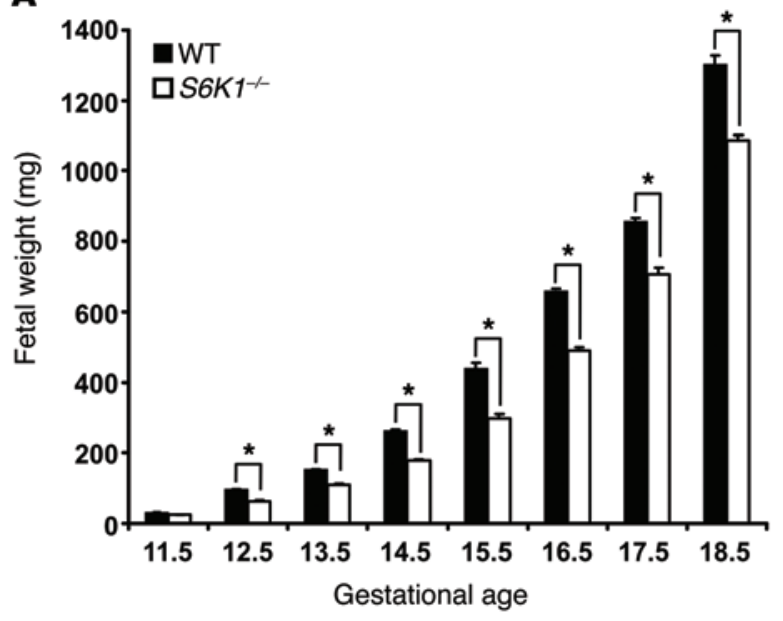

B

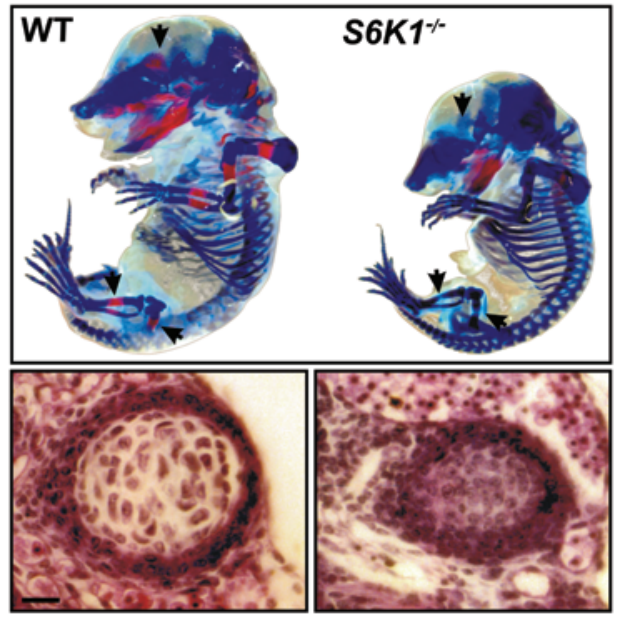

C

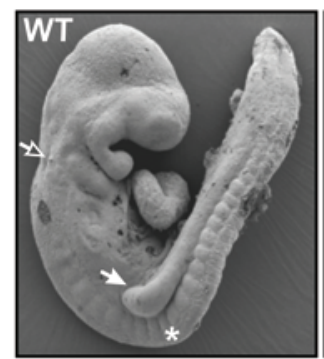

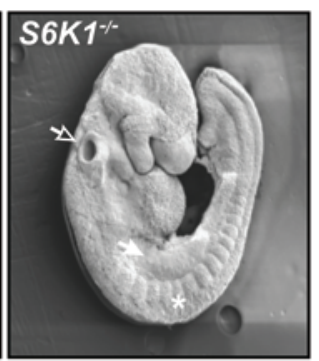

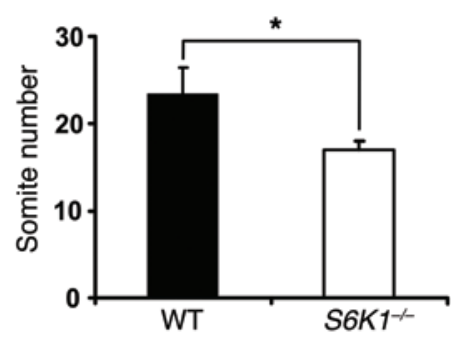

D

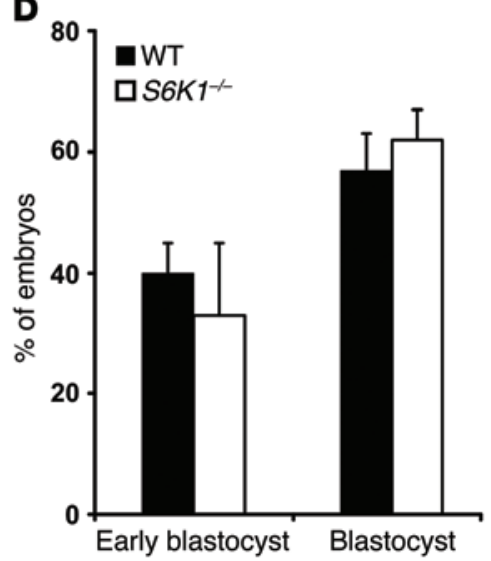

Figure 2. S6K1/- embryos are developmentally retarded and display IUGR. (A) Weight of WT and $56 K 1^{-1-}$ embryos at the indicated gestational ages.

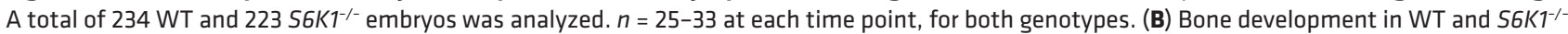
embryos. Top panel: Lateral view of skeleton at E16.5 analyzed for ossification, using alcian blue (cartilage) and alizarine red (bone). Arrows indicate ossification in the frontal bone of the cranium; in the fibula and tibia bone on the hind limb of WT embryo, the corresponding areas on the S6K1/- embryo are still cartilaginous. Bottom panels: Hypertrophied chondrocytes in cervical vertebrae from WT (left) but not in S6K1 1- (right) at E14.5. (C) Lateral view of E9.5 embryos (asterisk indicates somite) by scanning electron microscopy (left) and number of somites (right) ( $n=12$ per genotype). Note the open otic pit (open arrow) and the absence of a limb bud (filled arrow) in the S6K1-1- embryo. (D) Preimplantation development-stage analysis using 106 eggs from 7 WT mice and 45 eggs from 4 S6K $1^{-1-}$ mice. Scale bar: $25 \mu \mathrm{m}$. In A, C, and $\mathbf{D}$, values are given as mean \pm SEM. ${ }^{*} P<0.05$ vs. WT, unpaired $t$ test.

tissue, whereas none was detected in WT tissue sections (Figure 1C). Morphometric analysis of pancreatic tissue sections costained for insulin and glucagon (Figure 1D) revealed a $25 \%$ and a $27 \%$ reduction in $\beta$ cell number and size, respectively, in $S 6 \mathrm{~K}^{-/}$versus WT embryos (Figure 1, E and F). However, there was no significant difference in the size or number of glucagon-positive $\alpha$ cells, suggesting a selective effect on $\beta$ cells (Figure 1, E and F). The decrease in $\beta$ cell size was consistent with a $50 \%$ reduction in the insulin content of $S 6 \mathrm{K1}^{--}$versus WT embryos, normalized to embryonic body weight (Figure 1G). The reduction in insulin content and $\beta$ cell size during embryonic development persists throughout adult life, suggesting that the phenotype observed in adult $56 \mathrm{K1}^{-1-}$ mice arises from impaired embryonic pancreatic $\beta$ cell growth.

$S 6 \mathrm{~K}^{-1-}$ mice are developmentally retarded and display IUGR. To determine if the reduction in $\beta$ cell number and size observed in $S 6 \mathrm{~K}^{-/}$embryos was associated with IUGR, we examined embryonic body weights from E11.5-E18.5. The results show that $S 6 \mathrm{~K}^{-1-}$ embryos displayed IUGR as early as E12.5, with their weight reaching only $80 \%$ of that of WT embryos (Figure 2A). Previously, we demonstrated that flies deficient for the Drosophila orthologue of S6K1, $d S 6 \mathrm{~K}$, were not only severely reduced in size, but were strongly delayed in development (30). To establish whether IUGR was associated with a developmental delay in $S 6 \mathrm{~K}^{-1-}$ embryos, we analyzed cartilage formation and bone ossification during development. We found that IUGR was accompanied by a developmental delay - as measured at E16.5 by reduced staining for cartilage and bone, with alcian blue and alizarin red, respectively - as well as by deferred chondrocyte hypertrophy in the cervical vertebrae (Figure 2B). By E17, the differences in bone ossification and bone growth were less striking but not resolved (Supplemental Figure 1; supplemental material available online with this article; doi:10.1172/JCI77030DS1). As with the $\beta$ cell growth, the effects on skeletal development were equivalent in $S 6 \mathrm{~K}^{-/-}$mice obtained either from maternal heterozygous or null $S 6 K 1$ crosses. To determine if the delay in development was elicited at an earlier stage, we analyzed whole embryos by scanning electron microscopy at 

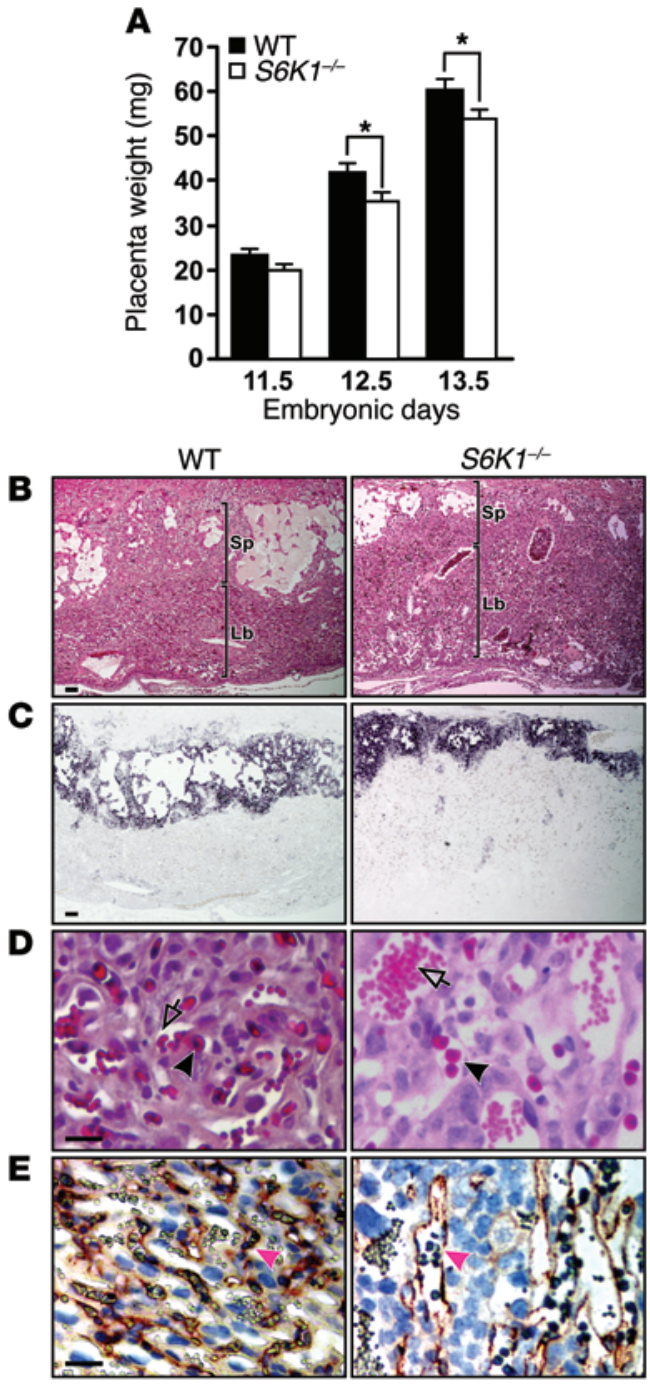

E9.5. We found that $S 6 \mathrm{~K}^{-1-}$ embryos had a reduced number of somites and a delay in otic pit closure, as well as the appearance of limb buds, indicating an approximate half-day delay in development (Figure 2C). Finally, we assessed preimplantation blastocysts to determine whether IUGR observed in $S 6 \mathrm{~K}^{-1-}$ embryos reflected an intrinsic defect in embryonic development. This analysis revealed no visible anomalies in the $S 6 \mathrm{~K}^{-/}$preimplantation blastocysts, with $60 \%$ of the eggs of both genotypes developing to the blastocyst stage and maturing by E3.5 (Figure 2D). Although a deficit in blastocysts cannot be excluded in contributing to $\mathrm{S} \mathrm{K}^{-1-}$ embryonic phenotype, the growth retardation arises at the time of, or immediately following, trophoblast differentiation and intrauterine implantation, strongly suggesting that it appears as a function of impaired extraembryonic tissue development.

Impaired placental development in S6 $\mathrm{K}^{-1-}$ mice. As nutritional restriction is associated with impaired trophoblast development and mTORC1 appears to play a critical role in placental function $(22,31)$, we questioned whether the absence of S6K1 could affect placental development. The placenta is composed of 3 distinct extraembryonic tissues largely derived from the fetus: an outer trophoblast giant-cell sheath, a middle spongiotrophoblast layer, and the innermost labyrinth (32). The labyrinth contains cells of
Figure 3. Abnormal placental development in S6K1-/- mice. (A) Reduced placental weight in S6K1-deficient mice from E11.5-E13.5 ( $n=5$-14 per genotype). (B-E) Placenta sections from WT and S6K1/- embryos at E13.5. (B) Labyrinthine trophoblast (Lb) and spongiotrophoblast (Sp) layers by H\&E staining; (C) Tpbp Sp-specific marker by ISH labelling. Note that the $\mathrm{Sp}$ layer is thinner in S6K1/- placenta (right). (D) Reduced intermingling of maternal (containing enucleated erythrocytes, open arrows) and embryonic blood vessels (identified by nucleated erythrocytes, filled arrows) in the Lb layer of $56 \mathrm{~K}^{-1-}$ placenta (right). (E) Anti-PECAM staining (brown) shows dilated fetal blood vessels, irregular in diameter in $56 \mathrm{~K}^{-1-}$ placenta (right). Filled arrows indicate nucleated erythrocytes. Scale bars: $25 \mu \mathrm{m}$. In A, values in are given as mean \pm SEM. ${ }^{*} P<0.05$ vs. WT, unpaired $t$ test.

both trophoblast and mesodermal origin that undergo branching morphogenesis to produce the large surface area required for the placental exchange of nutrients and gases (32). Morphological analysis revealed that $S 6 \mathrm{~K}^{-/-}$placentas weighed $12 \%-16 \%$ less than those of WT mice from E11.5-E13.5 (Figure 3A), whereas, the S6 $61^{-1-}$ embryos weighed $25 \%-36 \%$ less than those of WT mice during this same stage of development (Figure 2A). It is well documented that a reduction in placental size can directly impact the size of the embryo, due the placenta's ability to transfer nutrients from the mother to the fetus (33). These observations suggested that the negative effect of the loss of S6K1 on embryonic growth may be attributed to impaired placental development (see below). Histological examination of placentas from $S 6 \mathrm{~K}^{-1-}, S 6 \mathrm{~K}^{+1-}$, and WT embryos showed normal morphology of the giant cells that form a layer between the maternal decidual tissue and the embryonic labyrinth (Supplemental Figure 2, A-C). However, compared with WT and $S 6 K^{+/-}$placentas, the spongiotrophoblast layer of $S 6 \mathrm{~K}^{-1-}$ placentas was reduced in size, as assessed by H\&E staining (Figure 3, B and C, and Supplemental Figure 2, A-C, G, and $\mathrm{H})$. An intact spongiotrophoblast layer is required for normal development of the labyrinth, which secretes vascular endothelial growth factor to induce normal blood vessel function (32). Moreover, $\mathrm{H} \& \mathrm{E}$ staining revealed that the $S 6 \mathrm{~K}^{-/}$placentas appeared to have a slightly larger-sized labyrinth layer but displayed a sharp reduction in embryonic and maternal blood vessel association, with the fetal blood vessels highly dilated (Figure 3D). This result was confirmed by immunostaining of platelet/endothelial cell adhesion molecule-1 (PECAM-1) (Figure 3E and Supplemental Figure 2, D-F), again indicating a decreased vascular capacity of the labyrinth layer in $56 \mathrm{~K}^{--}$placentas. The decrease in blood vessel intermingling suggested restricted nutrient and oxygen exchange between the mother and the developing embryo, which could directly impact the size of the fetus (33). In addition, $S 6 \mathrm{~K}^{-/-}$ placentas displayed improperly positioned, trophoblast-specific, Tpbp-expressing cells in the labyrinth region at E19.5 (Supplemental Figure 2, I and J). The fact that the $S 6 \mathrm{~K}^{-1-}$ placental phenotypes observed were alike, regardless of the parental genotype, is consistent with the trophoblast playing a dominant role in the development of the placenta (33). Taken together, these results suggest that impaired placental development, as depicted by the defects in the spongiotrophoblast and labyrinthine layers, may be responsible for IUGR of $S 6 \mathrm{KI}^{--}$mice.

Rescue of IUGR, but not reduced $\beta$ cell size, by tetraploid WT placenta. Given the importance of the placenta in pancreatic $\beta$ cell growth and development $(27,34)$, we reasoned that the placental 


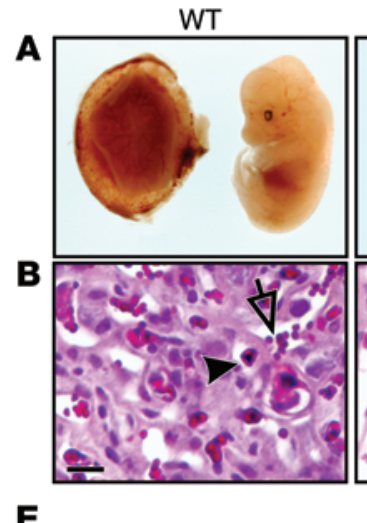

E

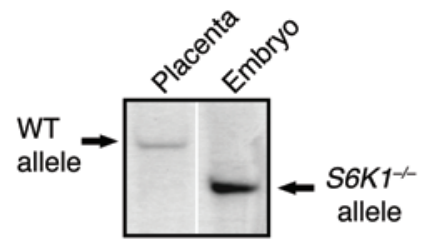

S6K $1^{-1-}$

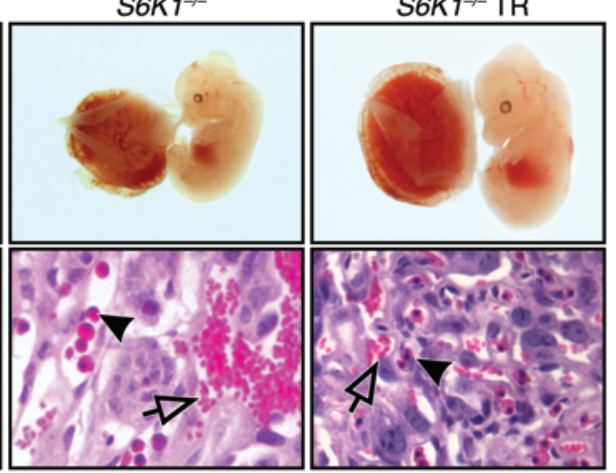

F

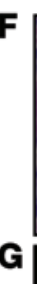

G

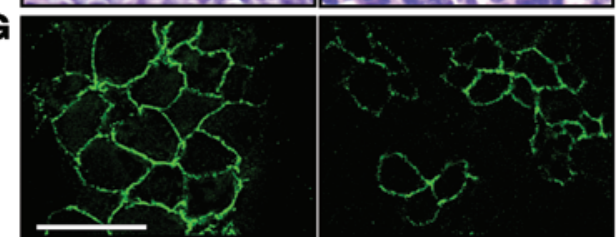

H

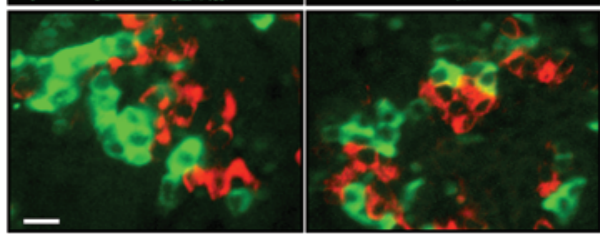

C

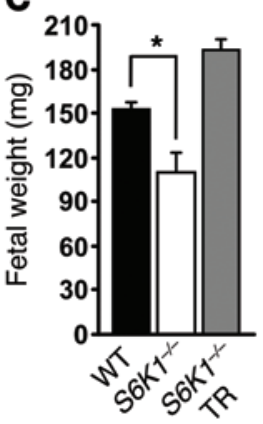

I
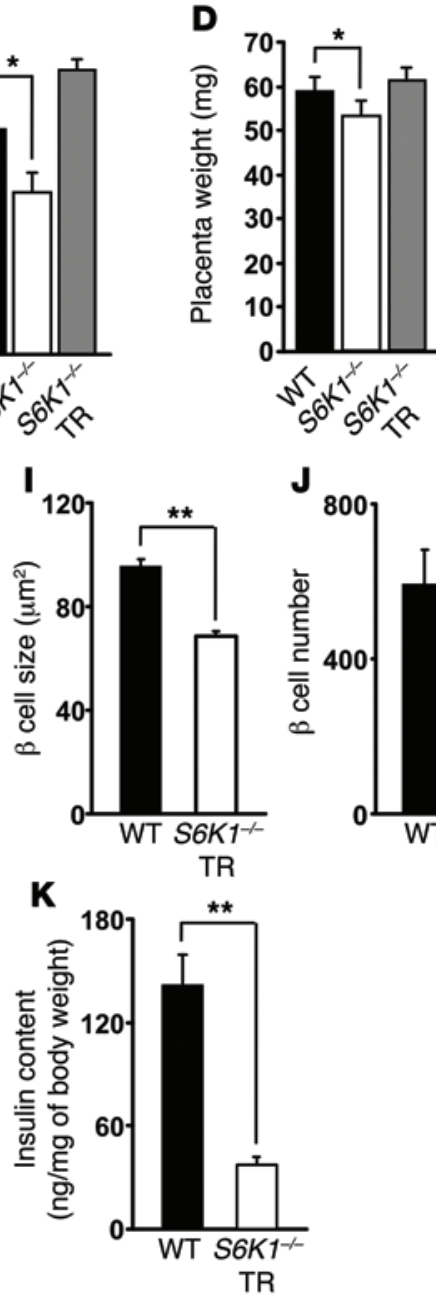

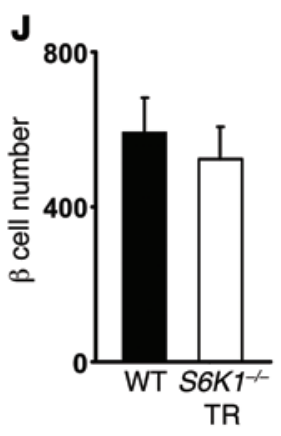

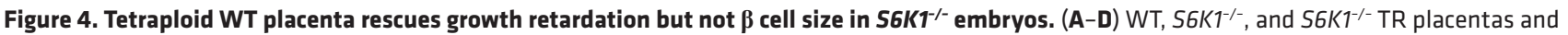
embryos at E13.5: (A) pictures representative of sizes; (B) histology by H\&E staining: S6K1 ${ }^{-1-}$ TR placenta reveals correct intermingling of maternal (open arrows) and embryonic blood vessels (filled arrows) in labyrinthine trophoblast (Lb); (C) Body weights ( $n=3-9$ per genotype). (D) Placenta weights ( $n=3-9$ per genotype). (E) Genotype of the tetraploid placenta and the ES cell-derived embryo from an S6K1 ${ }^{-1-}$ TR mouse by Southern blot analysis. The lanes were run on the same gel but were noncontiguous. (F and $\mathbf{G})$ Pancreas sections from E16.5 WT and S6K1 1/- TR embryos: (F) histology by H\&E staining; (G) glucose transporter GLUT2 by immunofluorescence (IF) staining; and (H) insulin (red) and glucagon (green) by IF staining. (I) Diminished $\beta$ cell size in S6K ${ }^{-1 /}$ TR pancreata, calculated on 56 determinations from WT embryos and 43 from S6K1-- TR embryos ( $n=3$ per genotype). (J) $\beta$ cell number in embryonic pancreata ( $n=3$ for per genotype, 18 sections per genotype). (K) Reduced insulin content in E16.5 S6K1 $1^{-1-}$ TR embryos ( $n=3$, from independent experiments) compared with WT embryos $(n=6)$ developed in surrogate mother mice. Scale bars: $25 \mu \mathrm{m}$. In C-K, values are given as mean \pm SEM. ${ }^{*} P<0.05$;

${ }^{* *} P<0.01$ vs. WT, unpaired $t$ test.

defect in $56 \mathrm{~K}^{-/}$mice was the cause of IUGR, resulting in impaired $\beta$ cell function. To test this hypothesis, we took advantage of tetraploid embryo complementation (35), such that $S 6 \mathrm{~K}^{-1-}$ embryonic stem cells (ES cells) were aggregated with tetraploid 2-cellstage WT embryos. This allows one to supply a WT placenta to ES cells during embryonic development (35). The extent to which tetraploid embryo complementation can salvage IUGR is underscored by the complete rescue of a homozygous mouse derived from ES cells of a lethal trophoblastic mutant (36). The ensuing embryos were then transplanted into foster CD1 mothers (35). In this model, WT tetraploid cells supply the extraembryonic placental trophoblasts and yolk sac endodermic cells but are excluded from the embryo, owing to their increased ploidy. In contrast, the diploid ES cells cannot develop into trophoblast tissues and are confined to the embryo proper (32). To initiate these studies, we derived 4 independent $S 6 \mathrm{~K}^{-1}$ ES cell lines (see Methods), and were able to obtain fetuses from one of them. Using this line, we obtained E13.5 $S 6 \mathrm{~K}^{-1 /}$ tetraploid rescue $\left(\mathrm{S} 6 \mathrm{KI}^{-1-} \mathrm{TR}\right)$ embryos, which developed to a size larger than $S 6 \mathrm{KI}^{-1-}$ embryos and even slightly larger than WT embryos. Both were cultured in vitro and transplanted in WT surrogate mothers (Figure 4, A-D). The larger-sized tetraploid embryo is consistent with previous studies, showing that tetraploid embryo complementation leads to increased embryonic weight, a phenotype termed hybrid vigor (37). The genotype of each tissue was confirmed by Southern blot analysis (Figure 4E). These results support the hypothesis that it is the failure of the $S 6 \mathrm{~K}^{-1-}$ trophoblasts to differentiate properly, which leads to impaired placental development, ultimately triggering IUGR. Such a phenotype has been described 


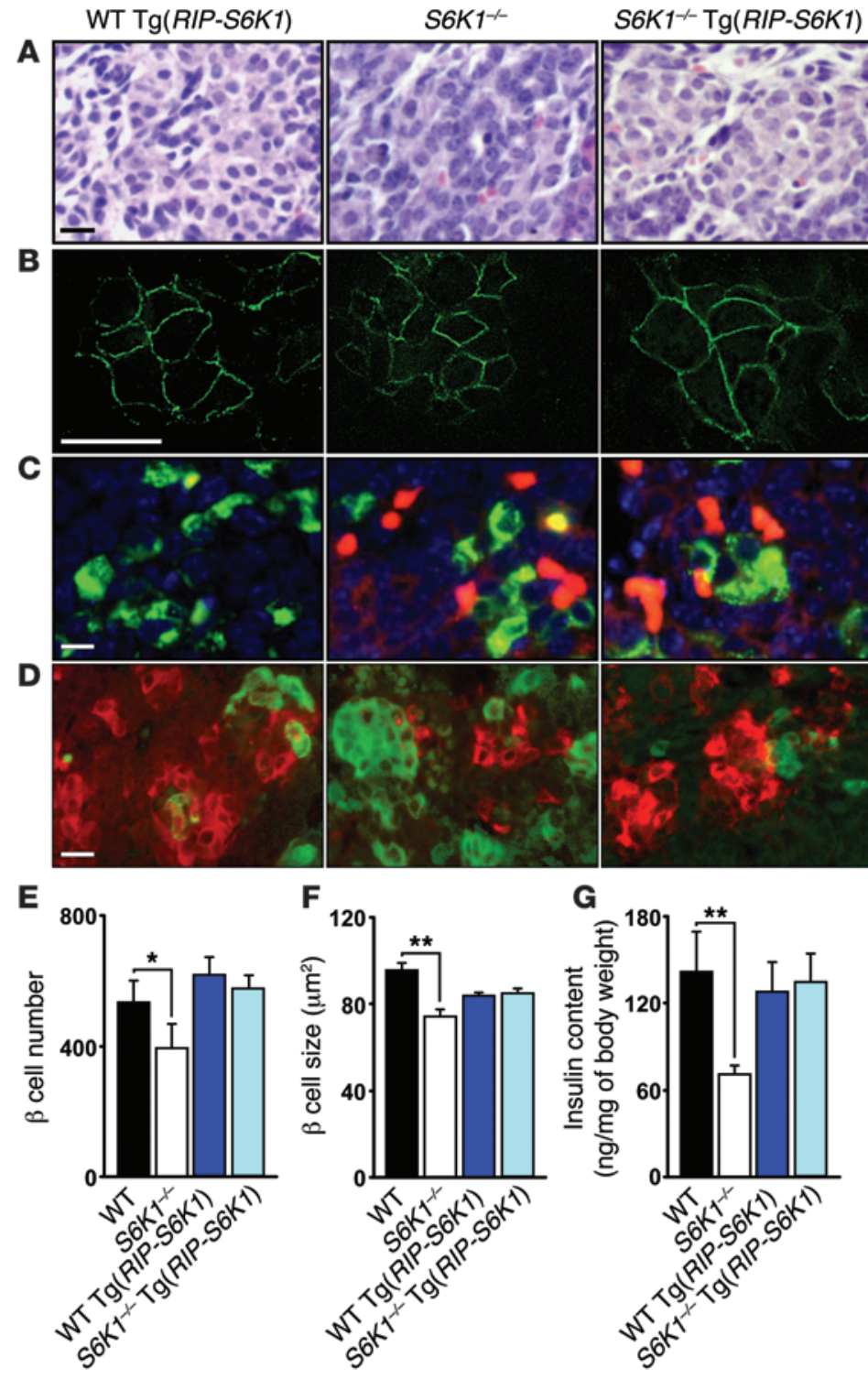

Figure 5. Pancreatic $\beta$ cell-specific expression of S6K1 restores diminished $\beta$ cell size and insulin content in S6K1/-- embryos. (A-D) Pancreas sections from WT $\operatorname{Tg}(R I P-S 6 K 1)$, S6K1 $1^{-1-}$, and S6K1 $1^{-1-} \operatorname{Tg}(R I P-S 6 K 1)$ embryos at E16.5: (A) histology by H\&E staining; (B) GLUT2 by immunofluorescence (IF) staining; (C) cleaved caspase-3 (red), insulin (green), and DAPI (blue), by IF; and (D) insulin (red) and glucagon (green), by IF staining. (E) $\beta$ cell number in pancreas. A total of $18 \mathrm{sec}$ tions from the middle of the pancreas was analyzed ( $n=3$ for per genotype from 3 independent crosses). (F) $\beta$ cell size, obtained from 29-51 determinations ( $n=3$ for per genotype). (C) Insulin content from embryonic pancreata $(n=3-10$ for per genotype). Scale bars: $25 \mu \mathrm{m}$. Values in $\mathbf{E}-\mathbf{G}$ are given as mean $\pm \mathrm{SEM}$. ${ }^{*} P<0.05$, ${ }^{* *} P<0.01$ vs. other genotypes, ANOVA.

in mouse KOs of other protein kinases (38). Consistent with the rescue being dependent on proper placental development, the placentas from E13.5 $S 6 \mathrm{~K}^{-/-}$TR embryos, unlike the $S 6 \mathrm{~K}^{-/-}$placentas, displayed typical WT structures with proper intermingling of blood vessels (Figure 4B), as well as normal weights (Figure 4D). These results indicate that the IUGR displayed by $S 6 \mathrm{~K}^{-{ }^{--}}$embryos results from impaired placental development. To determine the impact of a WT placenta on $S 6 \mathrm{~K}^{-1-} \beta$ cell development, we analyzed $S 6 \mathrm{~K}^{-1-}$ TR embryos at E16.5. Unexpectedly, the results of H\&E staining showed that the nuclei were still densely packed in the pancreas from $S 6 \mathrm{~K}^{-1-} \mathrm{TR}$ embryos, as compared with those from WT embryos (Figure 4F). These findings are consistent with the apparently smaller $\beta$ cell size revealed by GLUT2 transporter immunostaining (Figure 4G). Morphometric analysis of tissue sections costained with insulin and glucagon (Figure $4 \mathrm{H})$ confirmed that the WT tetraploid placenta did not rescue the reduction in $\beta$ cell size (Figure 4I). The cell number also appeared to be slightly reduced in $\mathrm{S}_{\mathrm{K}} \mathrm{K}^{-/-} \mathrm{TR}$ versus WT embryos, though the difference was not significant (Figure 4J). Compatible with the reduction in $\beta$ cell size, insulin content was still strongly reduced in $S 6 \mathrm{K1}^{-1-} \mathrm{TR}$ versus WT embryos (Figure $4 \mathrm{~K}$ ). Thus, the apparent reversion of the IUGR deficit in the tetraploid rescue, as determined by the restoration of a normal placenta phenotype (Figure 4B), does not appear to rescue the $\beta$ cell size deficit (Figure $4, \mathrm{~F}-\mathrm{I}$ ). The placenta derived from WT trophoblasts also appears to rescue $S 6 \mathrm{~K}^{-/-} \mathrm{TR} \beta$ cell number, but surprisingly not $\beta$ cell size, suggesting an independent role for S6K1 in $\beta$ cell growth.

S6K1 affect intrinsically embryonic $\beta$ cell size. Given the ability of tetraploid embryos to completely rescue placental development of ES cells of a lethal trophoblast mutant (36), it would imply that loss-of-S6K1 effects on embryonic $\beta$ cell size are independent of IUGR. If this is the case, it raises the possibility that $\mathrm{S} 6 \mathrm{~K} 1$ controls this response in a cell-autonomous manner. We have previously demonstrated that Drosophila dS6K plays an intrinsic role in controlling cell size in specific tissues, including the wing and the eye $(30,39)$, which we also found later to be the case in mouse embryonic fibroblasts (MEFs) (40). Moreover, others have shown that targeted $\beta$ cell expression of a constitutively active $S 6 K 1 \mathrm{cDNA}$ leads to an increase in $\beta$ cell size (16). To test this possibility, we first generated a transgenic mouse line expressing a myc-epitope-tagged $S 6 K 1$ cDNA driven by the rat insulin II promoter (RIP, RIP-S6K1) (41). By breeding WT $\mathrm{Tg}(R I P-S 6 K 1)$ with $S 6 \mathrm{~K}^{-/-}$mice, we obtained $S 6 \mathrm{~K}^{-/-} \mathrm{Tg}(R I P-S 6 K 1)$ mice. Although we could not detect the myc-epitope tag by immunofluorescence, we could detect S6K1, which was coexpressed with insulin in $S 6 \mathrm{~K}^{-1-} \mathrm{Tg}(R I P-S 6 K 1) \beta$ cells of E16.5 embryos, but not in those of $S 6 \mathrm{~K}^{-/-} \mathrm{E} 16.5$ embryos (Supplemental Figure $3)$. Reexpression of the RIP-S6K1 transgene in $\beta$ cells did not rescue fetal weight (Supplemental Figure 4), whereas, in striking contrast to $S 6 \mathrm{~K}^{-/}-\beta$ cells of E16.5 embryos, $\beta$ cells of E16.5 $S 6 \mathrm{~K}^{-/-} \mathrm{Tg}(R I P-S 6 K 1)$ embryos were equivalent in size to those derived from E16.5 WT $\mathrm{Tg}(R I P-S 6 K 1)$ embryos, as assessed by either H\&E or GLUT2 staining (Figure 5, A and B, respectively). Moreover, even though staining with cleaved caspase-3 revealed increased apoptosis in $\beta$ cells of $S 6 \mathrm{~K}^{-/-} \mathrm{Tg}(R I P-S 6 K 1)$ versus WT $\mathrm{Tg}(R I P-S 6 K 1)$ embryos, apoptosis occurred mainly outside of embryonic $\beta$ cells (Figure $5 \mathrm{C})$. Morphometric analysis of insulin and glucagon costaining of tissue sections (Figure 5D) showed that the RIP-S6K1 transgene was sufficient to rescue $\beta$ cell number and size in E16.5 $S 6 \mathrm{~K}^{-/-}$embryos (Figure 5, E and F, respectively). The rescue of $\beta$ cell number and size by RIP-S6K1 transgenic expression was paralleled by a restoration in $\beta$ cell insulin content (Figure $5 G$ ). 
A

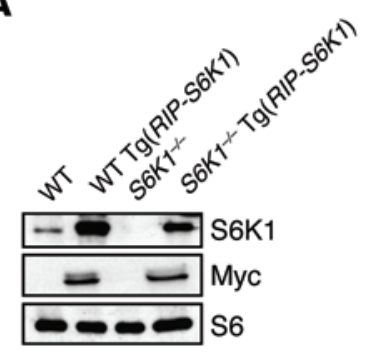

B

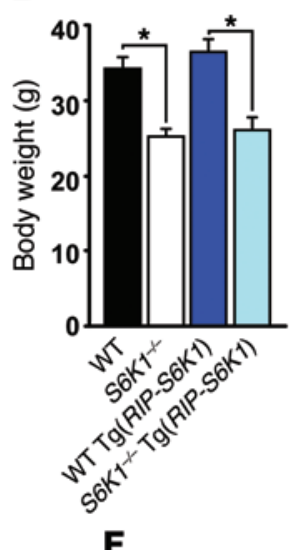

E

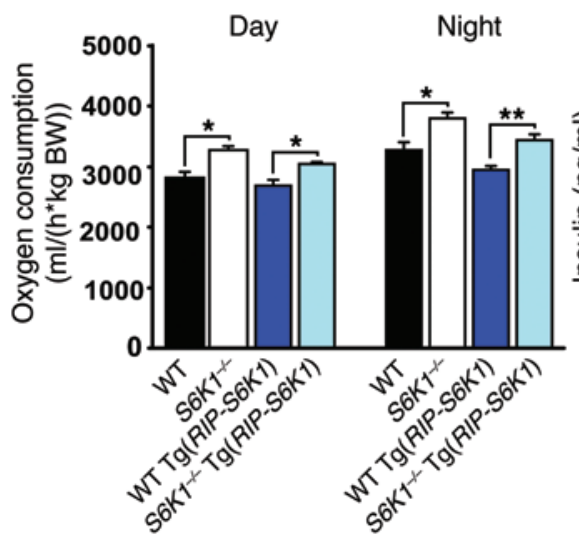

$\mathbf{F}$

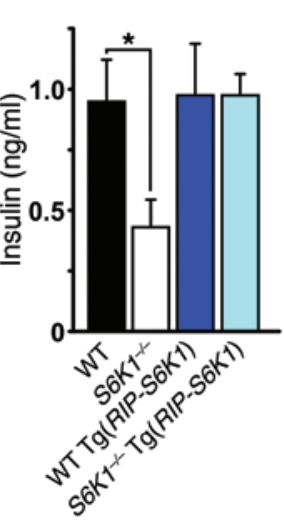

C

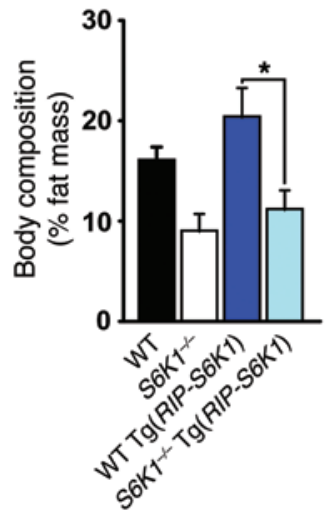

G
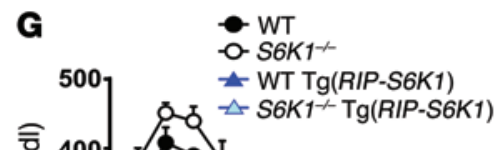

D

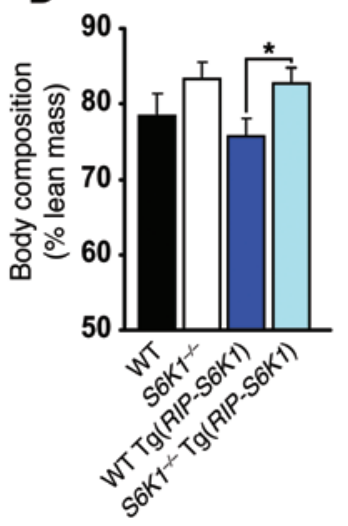

H

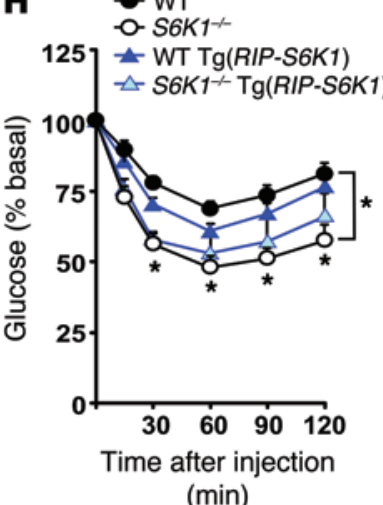

Figure 6. Pancreatic $\boldsymbol{\beta}$ cell-specific expression of S6K1 improves glucose tolerance. (A) RIP-S6K1 transgene expression in islet extracts by Western blot analysis detecting Myc-tag and S6K1 protein. (B) Body weight was measured in 8-month-old male mice ( $n=6-12$ per genotype). (C-H) Male mice were analyzed at 3-6 months of age for (C) percent of fat-mass and (D) lean mass. They were normalized by body weight and determined by NMR analysis ( $n=5-9$ mice of per genotype); (E) increased oxygen consumption in S6K1 transgenic mice measured either during the day or night as indicated ( $n=4-9$ mice per genotype). (F) Plasma insulin concentrations in mice fasted for 6 hours ( $n=6-10$ mice of per genotype; experiments were performed twice). (G) Blood glucose concentrations before and after i.p. injection of $2 \mathrm{~g}$ D-glucose per kg body weight in mice fasted overnight $(n=5-9$ mice per genotype). (H) Insulin tolerance test after 3 hours fasting: plasma glucose concentration before and after intraperitoneal injection of insulin ( $0.75 \mathrm{U}$ per kg body weight; $n=5-9$ mice per genotype). Values in $\mathbf{B}-\mathbf{H}$ are given as mean $\pm \mathrm{SEM} .{ }^{*} P<0.05$ vs. other genotypes, ${ }^{* *} P<0.01 \mathrm{vs}$. other genotypes, ANOVA.

These studies strongly support the hypothesis that the reduction in $\beta$ cell number and size explains the reduction in insulin content in $S 6 \mathrm{~K}^{-1-}$ embryos (Figures 1 and 5).

RIP-S6K1 transgene expression improves glucose tolerance. Western blot analysis of adult 3- to 5-month-old mice revealed that the expression of the Myc-epitope-tagged S6K1 was maintained in both WT $\mathrm{Tg}(R I P-S 6 \mathrm{~K} 1)$ and $S 6 \mathrm{~K}^{-1-} \mathrm{Tg}(R I P-S 6 \mathrm{~K} 1)$ mice (Figure $6 \mathrm{~A})$. Following birth, reexpression of the RIP-S6K1 transgene in S6 $61^{-1-}$ mice did not rescue the reduction in body size, nor were there any obvious alterations in the body composition in terms of either fat mass or lean mass, when compared with $S 6 \mathrm{KI}^{-/}$mice (Figure 6, B-D). Likewise RIP-S6K1 transgene expression had little effect on whole-body energy expenditure (EE) when compared with $S 6 \mathrm{~K}^{-1-}$ mice (Figure 6E). In contrast to these observations, RIP-S6K1 transgene expression in $\beta$ cells restored circulating insulin in $S 6 \mathrm{~K}^{-/}$mice to levels similar to those observed in either WT $\mathrm{Tg}($ RIP-S6K1) or WT mice (Figure 6F). Previously, we had shown that $S 6 \mathrm{~K}^{-/}$mice are mildly glucose intolerant, which we attributed to their hypoinsulinemia (14). However, despite hypoinsulinemia, such mice maintain glucose homeostasis and insulin sensitivity
(9), apparently due to both reduced insulin levels and adiposity, as well as the loss of the negative feedback loop from S6K1 to IRS1 in muscle and adipose (14). Consistent with these findings, RIP-S6K1 transgene expression in $S 6 \mathrm{KN}^{--}$mice not only rescued the mild glucose intolerance, but dramatically enhanced this response over that of WT RIP-S6K1 or WT mice (Figure 6G). It should be noted that the expression of $\mathrm{S} 6 \mathrm{~K} 1 \mathrm{in} \beta$ cells, but not its levels of expression (Figure 6A), correlated with the restoration of circulating insulin levels (Figure 6F), suggesting that a threshold of S6K1 activity may be critical for this response (see below). Importantly, increased insulin levels in $S 6 \mathrm{~K}^{-1-} \mathrm{Tg}(R I P-S 6 \mathrm{~K} 1)$ mice neither affected their adiposity nor their insulin sensitivity (Figure 6, C and H, respectively). Therefore the increase in glucose tolerance displayed by $S 6 \mathrm{~K}^{-1-} \mathrm{Tg}(\mathrm{RIP}-\mathrm{S} 6 \mathrm{~K} 1)$ mice, as compared with $S 6 \mathrm{~K}^{-1-}$ mice, appears to be due to restoration of normal circulating levels of insulin.

RIP-S6K1 transgene expression restores $\beta$ cell size and S6 phosphorylation. Consistent with the restoration of normal insulin levels, $\mathrm{H} \& \mathrm{E}$ and insulin staining of adult islets showed a clear increase in $\beta$ cell size of $S 6 \mathrm{~K}^{-1-} \mathrm{Tg}(R I P-S 6 \mathrm{~K} 1)$ mice (Figure 7, $\mathrm{A}$ and $\mathrm{B}$ ), which was confirmed by morphometric analysis of insulin-stained cells 


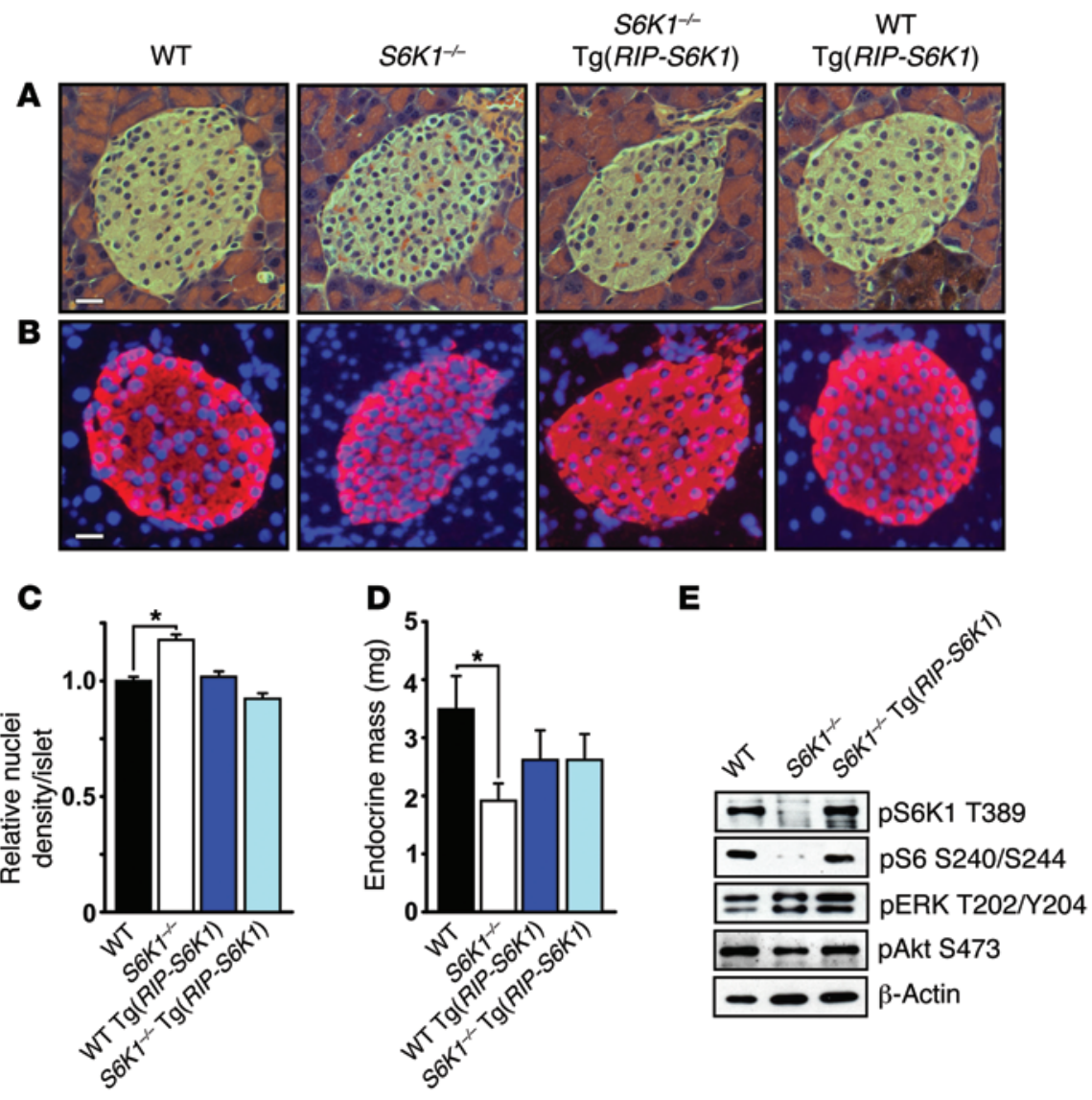

Figure 7. Pancreatic $\beta$ cell-specific expression of S6K1 restores diminished $\beta$ cell size and $\mathrm{S} 6$ phosphorylation in adult $56 \mathrm{KT}^{-1-}$ mice. (A and B) Pancreas tissue sections from adult mice at 3-6 months of age: (A) histology, by H\&E staining; (B) $\beta$ cell size in islets, by Hoechst staining for DNA (blue) and immunofluorescence (IF) staining for insulin (red). (C) $\beta$ cell density in islets was assessed by counting the number of nuclei normalized for islet area ( $n=32-42$ islets in 3-5 mice per genotype). (D) Endocrine mass calculated from 13-24 determinations ( $n=3-5$ mice per genotype). (E) Phosphorylated S6K1 T389 (pS6K1 T389), phosphorylated S6 S240/S244 (pS6 S240/S244), phosphorylated Akt (pAkt S473), and phosphorylated ERK 1 and 2 T202/Y204 (pERK T202/Y204) by Western blots analyses. Scale bars: $50 \mu \mathrm{m}$. Values in $\mathbf{C}$ and $\mathbf{D}$ are given as mean \pm SEM. ${ }^{*} P<0.05$ vs. other genotypes, ANOVA.

(Figure 7C), as well as by a significant increase in total endocrine mass (Figure 7D), although it did not reach that of WT mice. The RIP promoter has been reported to be expressed in the hypothalamus (42), and recent studies have shown that hypothalamus can control insulin secretion by $\beta$ cells (43). However, we did not detect expression of S6K1 in hypothalamus in $S 6 \mathrm{~K}^{-/-} \mathrm{Tg}(R I P-S 6 \mathrm{~K} 1)$ mice, potentially due to the genomic integration site or an epigenetic modification of the transgene (Supplemental Figure 5). Moreover, despite the known effects of S6K1 in the negative feedback loops to suppress both protein kinase B (PKB, also known as AKT) (9) and ERK (44), neither PKB S473 nor ERK T202/Y204 phosphorylation appeared to be affected by loss of S6K1 or its reexpression in $S 6 \mathrm{~K}^{-1-} \mathrm{Tg}(R I P-S 6 K 1)$ mice (Figure 7E). It may be that the role of the feedback loop can only be observed under conditions of nutrient overload, as we found for PKB (9). Finally, it has been reported that mice harboring a knockin of $40 S$ RPS6 cDNA, where the 5 serine RPS6 phosphorylation sites (45) are substituted by alanines, display hypoinsulinemia and experience $\beta$ cell size reduction (46). This finding led to the suggestion that the size reduction observed in the $\beta$ cells of $S 6 \mathrm{~K}^{-1-}$ mice (14) is due to a decrease in RPS6 phosphorylation (46). Consistent with this observation, in islets from $S 6 \mathrm{~K}^{-/-}$mice, S6K1 phosphorylation is absent and S6 phosphorylation is severely reduced. However, in islets from $S 6 \mathrm{~K}^{-/-} \mathrm{Tg}(R I P-$ S6K1) mice, S6K1 T389 and S6 S240/S244 phosphorylation are both restored to levels similar to those observed in WT mice (Figure 7E). Taken together, the results suggest that the effects of S6K1 on pancreatic $\beta$ cell size may be mediated, at least in part, by increased S6 phosphorylation.

\section{Discussion}

Given the potential role of S6K1 inhibitors in the treatment of T2DM, we set out to determine whether the effects on $\beta$ cell size and hypoinsulinemia observed in $S 6 \mathrm{~K}^{-1-}$ mice were due to IUGR or were mediated by an intrinsic $\beta$ cell defect. The results demonstrate that S6K1 deficiency leads to IUGR, but independently affects $\beta$ cell size, in a cell-autonomous manner. Although it is generally accepted that a deficiency in the placental nutrient supply leads to IUGR and subsequent lesions in $\beta$ cell development (18), others have recently reported in an ovine model of IUGR that following midgestation, the stage at which IUGR is diagnosed in humans, there is already a decrease in $\beta$ cell proliferation and fetal insulin levels (25). From these observations, they hypothesize that impaired $\beta$ cell development and decreased insulin levels may be a cause rather than an effect of IUGR (25). Nevertheless, the RPS6 knockin mice, harboring serine to alanine substitutions in the 5 RPS6 phosphorylation sites, are apparently of normal size at birth, despite hypoinsulinemia and reduced $\beta$ cell size (46). In agreement with the latter finding, we show that when $S 6 \mathrm{~K}^{-/-}$embryos develop with tetraploid WT placentas, IUGR is rescued, but $\beta$ cell growth and function remain impaired (Figure 4). However, in contrast to the RPS6 knockin mice, our results also suggest that loss of S6K1 activity independently induces IUGR. We show that IUGR can be detected at E9.5 in S6K1/- mice (Figure 2) long before the onset of $\beta$ cell growth defects at E16.5, when insulin-producing pancreatic islets start forming. Moreover, when S6K1 is reintroduced in the $\beta$ cells of $S 6 \mathrm{~K}^{-/-}$mice, there is no impact on IUGR, despite the correction in $\beta$ cell size and insulin levels (Figures 5-7). 
It should be noted that in the mouse, deletion of Mtor - the S6K1 T389 kinase - abrogates development at E5.5, as it is required for trophoblast differentiation, outgrowth, and invasion of the uterine stroma during placental development $(22,31,47)$. Deletion of S6K1 may have less damaging developmental effects because it represents only one of the multiple downstream targets of mTOR. Taken together, these findings support the possibility that nutrient deprivation during early development may use independent routes to affect IUGR and impair $\beta$ cell function.

mTORC1 plays a key role in the activation of S6K1 by providing a docking site for phosphoinositide-dependent protein kinase (PDK1), the T229 S6K1-activation loop kinase (48). Previous studies have shown that mice or embryos lacking PDK1 exhibit both reduced $\beta$ cell number and size $(49,50)$. PDK1 also serves as the S308 PKB-activation loop kinase. As PKB mediates the canonical PI3K signaling pathway to mTORC1, this suggests that PDK1 plays a key role in 2 distinct pathways leading to S6K1 activation: one through nutrients and the other through hormone-mediated PKB activation. The effect on cell number, but not cell size, observed in PDK1-deficient $\beta$ cells is largely rescued by crossing the PDK1deficient mice with mice haploinsufficient for FoxO1, whose activity is negatively regulated by PKB phosphorylation (49). In line with this finding, mice lacking rictor, an essential component of the mTORC2 required for PKB-S473 phosphorylation, exhibit reduced $\beta$ cell number and increased FoxO1 activity (51). These observations led to the hypothesis that the effects of PDK1 deficiency on cell number are regulated through suppression of PKB, whereas those on cell size are regulated by S6K1 (49). Consistent with the effects of S6K1 on $\beta$ cell size, TSC1/TSC2 and Rheb (52) - upstream effectors of mTORC1/S6K1 - have been implicated in this response, and ectopic expression of a constitutively active S6K1 transgene in $\beta$ cells results in increased $\beta$ cell size (16). Genetic studies in mice suggest that the size reduction observed in the $\beta$ cells of $S 6 \mathrm{K1}^{-1-}$ mice is mediated by a decrease in RPS 6 phosphorylation (46), which has been implicated in the recruitment of mRNAs to the cap-binding complex translation initiation complex (53). Nevertheless, it should be noted that the effects of the loss of RPS6 phosphorylation on $\beta$ cell size are based on a whole-animal replacement with the multiple-alanine site RPS6 mutant, such that the effects on $\beta$ cell size may not be cell autonomous. At this stage, it would be informative to determine whether the effects of S6K1 on $\beta$ cell size are meditated through RPS6 by generating a $\beta$ cell-specific knockin of the RPS6 alanine allele.

Earlier studies from this laboratory showed that S6K1-deficient mice exhibit mild glucose intolerance, which was attributed to reduced $\beta$ cell size, leading to decreased glucose-stimulated insulin secretion (14). From the studies described here, the reduction in $\beta$ cell size does not appear to be mediated through either PKB or ERK, but most likely through reduced RPS6 phosphorylation (Figure $7 \mathrm{E}$ ). We initially attributed the mild effect on glucose intolerance to the fact that S6K1-deficient mice were still able to increase circulating insulin levels in answer to a glucose challenge, albeit less robustly (5). However, our later studies revealed that the ability of S6K1-deficient mice to maintain glucose homeostasis could also be explained, in part, by increased insulin sensitivity $(9,14)$. This effect was particularly evident when mice were challenged with an $\operatorname{HFD}(9,14)$. WT mice became insulin resistant, whereas
S6K1-deficient mice remained insulin sensitive, as they did on a normal chow diet $(9,14)$. Here we show that reexpression of S6K1 in the $\beta$ cells of $S 6 \mathrm{~K}^{-/-} \mathrm{Tg}(R I P-S 6 K 1)$ mice dramatically enhances glucose tolerance over that of WT mice (Figure 6G) by restoring normal plasma insulin levels (Figure $6 \mathrm{~F}$ ) under conditions where reduced adiposity (Figure 6C) and increased insulin sensitivity displayed by $S 6 \mathrm{K1}^{-/-}$mice are maintained (Figure $6 \mathrm{H}$ ). The observation that rapamycin does not have an inhibitory effect on acute insulin secretion (54) but can rapidly increase insulin sensitivity in obese rats (55) initially raised the possibility of employing the drug as an insulin sensitizer. However, chronic treatment of posttransplant patients with rapamycin has been associated with impaired glucose tolerance and T2DM (56), due in part to $\beta$ cell toxicity (57). Unlike in the case of $S 6 K 1$ deletion, we observe a similar phenotype in mice where we have conditionally deleted the Mtor gene in $\beta$ cells (J. Park, S.H. Um, and S.C. Kozma, unpublished observations). Moreover, others have provided evidence that insulin resistance caused by chronic treatment of mice with rapamycin is due to disruption of mTORC2 and not inhibition of mTORC1 (58). Thus the more deleterious effects of rapamycin could be attributed to the inhibition of multiple mTORC1 substrates, in addition to S6K1 (57), and its ability to inhibit mTORC2 (58). This argument is consistent with preliminary studies showing that in cell culture, compared with depletion of S6K1, rapamycin treatment leads to a more profound and lasting inhibition of the negative feedback loop to IRS1/2, as measured by insulin stimulation of PKB (K. Masuda and G. Thomas, unpublished observation). These findings, and the mild glucose intolerance displayed by $S 6 \mathrm{~K}^{-/-}$mice, raise the possibility that a selective inhibitor of S6K1 may have a clinical window of efficacy as an insulin sensitizer, beyond that of mTORC1 and mTORC2 inhibition.

\section{Methods}

Mice. S6 $\mathrm{K}^{-1-}$ mice on C57BL/6J background (9) were obtained from heterozygous or homozygous parental crosses, as indicated for the different methods. Genotyping was performed on tail DNA - or DNA derived from dissected embryos and placentas, in the case of tetraploid embryo complementation studies - by Southern blot analysis or PCR. The PCR primers corresponded to: $S 6 K 1$ forward, 5'-GTAGGGCACTTAAATGACCAC-3'; S6K1 reverse， 5'-TGTCCCTATTAAT-GCTCAAGG-3'; neo reverse, 5'-GCCTTCTTGA CGAGTTCTTCTGAG-3'.

Histological analysis. WT, $S 6 \mathrm{~K}^{+/-}$, and $\mathrm{S} \mathrm{K}^{-{ }^{--}}$mouse embryos and placentas were collected and fixed in $10 \%$ formalin overnight at $4^{\circ} \mathrm{C}$. Fixed samples were embedded in paraffin, and $5-\mu \mathrm{m}$ sections were cut and mounted on slides to generate a series of 6 slides with comparable adjacent sections. The average number of slides collected were 90-100 from pancreata per genotype using 3 heterozygous and 4 homozygous mouse matings. For morphological analyses, slides of each series were H\&E stained. For immunofluorescence, sections of embryonic and adult pancreata were stained with rabbit anti-glucagon (1:50, Invitrogen), guinea pig anti-insulin (1:400, Millipore), and rabbit anti-Glut2 (1:200, provided by B. Thorens) antisera. Detection was performed using Alexa Fluor 488 and 594 (Invitrogen). Morphometric analyses and cell counting were done using ImagePro Plus software (Media Cybernetics). Insulin and glucagon staining was performed using 15-16 slides per pancreas, representing $1 / 6$ of the organ. Forty-five to 52 slides were analyzed per genotype. To calculate the 
mean size of individual $\alpha$ and $\beta$ cells, a defined area was divided by the number of cell nuclei positive for either insulin or glucagon, as previously described (14). Apoptosis was determined in pancreatic sections stained for insulin (guinea pig anti-swine insulin, 1:800, Dako) and cleaved caspase-3 (rabbit anti-cleaved caspase-3, 1:50, Cell Signaling Technology) as described (52). Apoptotic cells were identified by costaining for insulin and cleaved caspase-3. Three sections per pancreas were examined, and at least 50-100 insulin-stained cells were counted for each animal. IHC and ISH were performed using placental tissue sections from the middle of each placenta. For anti-PECAM-1 staining, the sections were incubated with $0.1 \%$ trypsin after rehydration for 12 minutes at $37^{\circ} \mathrm{C}$, followed by 20 minutes incubation with $2 \mathrm{~N} \mathrm{HCl}$. Sections were then incubated overnight at $4^{\circ} \mathrm{C}$ with rat monoclonal anti-PECAM-1 (1:50, Pharmingen). Biotinylated horse anti-rat (Vector Laboratories) was used as the secondary antibody, followed by incubation with the $\mathrm{ABC}$ reagent (Vector Laboratories), detection with DAB (Vector Laboratories), and nuclear counterstaining with hematoxylin. The endocrine mass was quantified using the following equation: $\beta$ cell mass $=$ pancreas weight $(\mathrm{mg}) \times$ relative insulin surface (total islet area $\mu \mathrm{m}^{2} /$ total pancreas area $\left.\mu \mathrm{m}^{2}\right) \times 100$.

ISH analysis. The trophoblast-specific protein $\alpha(T p b p /-4311)$ gene was used as a molecular marker of spongiotrophoblast cells (59). Placenta sections of WT, $S 6 \mathrm{~K}^{+/-}$, and $S 6 \mathrm{~K}^{-/-}$embryos, from both heterozygous or homozygous matings, were rehydrated and permeabilized using $20 \mu \mathrm{g} / \mathrm{ml}$ proteinase $\mathrm{K}$ in $10 \mathrm{mM}$ Tris pH8/20 mM EDTA for 15 minutes at room temperature, fixed in $4 \%$ paraformaldehyde $/ 0.2 \%$ glutaraldehyde, and dehydrated in a graded methanol series. Antisense and sense riboprobes were generated by in vitro transcription using the DIG RNA Labeling Kit (Roche Diagnostics) following the manufacturer's instruction. NBT (Nitroblue tetrazolium chloride) and BCIP (5-Bromo-4-chloro-3-indoyl-phosphate, 4-toluidine salt), both from Roche Diagnostics, were used as the substrate for visualization.

Insulin content in blood and embryonic pancreata. Blood samples from adult mice issued from both heterozygous and homozygous matings were collected and centrifuged. Embryonic pancreata from each genotype obtained from both heterozygous and homozygous matings were placed into PBS and then sonicated 3 times for 10 seconds each time. Insulin concentration in the plasma or in pancreas extracts was measured using the ultrasensitive insulin ELISA kit (Crystal Chem Inc.) or by radioimmunoassay (Millipore), respectively.

Embryonic growth analysis. For embryo staging, the day of vaginal plug appearance was considered E0.5. Embryos were obtained from 4 heterozygous and 26-32 homozygous crosses for WT and $S 6 \mathrm{~K}^{-/-}$mice, respectively. For developmental analyses of growth, embryos and placentas were dissected from pregnant mice, patted dry, and weighed on a microbalance. For embryos obtained from heterozygous parental crosses, samples were collected and genotyped.

Preimplantation development in vitro. Following superovulation and mating of homozygous female mice with homozygous male mice, E1.5 or E3.5 embryos were collected and individually cultured in M16 medium, as described (60). The morphology of the embryos was recorded.

Skeletal staining. Embryos were eviscerated, skinned, fixed in ethanol, and stained with alcian blue 8GS (cartilaginous elements) and alizarin red $\mathrm{S}$ (mineralized elements) for 3-5 days. The tissues were cleared with $1 \% \mathrm{KOH}$, and the skeletons were stored in glycerol. Embryos were obtained from 3 heterozygous and 4 homozygous crosses per genotype.
Scanning electron microscopic analysis. Following homozygous mouse mating, embryos were fixed in $1.25 \%$ glutaraldehyde, $1 \%$ paraformaldehyde in $0.08 \mathrm{M}$ cacodylate buffer containing $0.02 \% \mathrm{CaCl}_{2}$ for 1 hour at room temperature, then overnight at $4^{\circ} \mathrm{C}$. They were postfixed in $1 \% \mathrm{O}_{\mathrm{S}} \mathrm{O}_{4}$ in water, washed, and dehydrated by alcohol. Scanning electron microscopic analysis was performed as described (9).

Establishment of $S 6 \mathrm{~K}^{-/-}$ES cells. S6 $6 \mathrm{~K}^{-/-}$embryos, obtained from homozygous parental crosses, were flushed at the morula stage and incubated overnight in M16 medium. On the next day, blastocysts were transferred to 6-cm dishes coated with inactivated mouse fibroblasts and 5637 cells (ATCC HTB9) to facilitate ES cell development. A few days later, the inner cell masses (ICMs) were collected with a glass pipette, treated with trypsin (Invitrogen) for 10 minutes at RT, and further propagated on inactivated fibroblasts. The medium used throughout the process was KO-DMEM supplemented with pen/strep/ glutamine, gentamycin (Invitrogen), $\beta$-mercaptoethanol (SigmaAldrich), LIF (Novartis), and 15\% FBS (PAN-Biotech GmbH).

Aggregation of tetraploid WT embryos with diploid S6K1-/- ES cells. WT embryos were recovered at the 2-cell stage (E1.5). The blastomeres were fused by electrofusion (60), and the resulting tetraploid embryos were cultured for 48 hours at $37^{\circ} \mathrm{C}, 5 \% \mathrm{CO}_{2}$, and $100 \%$ humidity in M16 medium (60). Next, the zona pellucida was removed from the 4-cell-stage tetraploid embryos by Tyrode's Acid treatment and further cultured in microdrops (60). Three independent $S 6 \mathrm{~K}^{-1-}$ ES cell clones were brought to single-cell suspension by a 5 -minute trypsin treatment (Invitrogen). The $S 6 \mathrm{~K}^{-/-}$ES cell suspensions were left to reaggregate into small clumps of 10-15 ES cells and placed in separate wells containing 2 tetraploid embryos, as described (60). The next day, blastocyst-stage embryos were harvested from the wells and implanted into the uteri of E2.5 pseudopregnant-recipient CD1 outbred female mice. This technique allows for the development of embryos in utero; however, it generates less than $5 \%$ living birth, and mice die within hours after birth (37). Therefore, analyses were performed at E13.5 and E16.5.

Generation of transgenic mice expressing S6K1 in pancreatic $\beta$ cells. The RIP-S6K1 DNA construct consisted of a 720-bp fragment of RIP driving transcription of a $m y c-S 6 K 1$ cDNA. RIP-S6K1 DNA was injected into B6CF2 - second-generation (F2) obtained from the crosses between $\mathrm{C} 57 \mathrm{Bl} / 6 \mathrm{~J}$ and BALB/C mice - fertilized eggs. Founders were identified by PCR analysis, and germline transmission was confirmed by Southern blot analysis. Genotyping was performed by PCR using primers derived from RIP and $S 6 K 1 \mathrm{cDNA}$ sequences as follows: Forward, 5'-CAGGCCACCCAGGAGCCCC-3'; reverse 1, 5'-GCATGATGTTCTC CGGCTTC AGG-3'; reverse 2, 5'-GTAAATGCCCC-AAAGCCATGGAG-3'. The transgenic mice were backcrossed for 6 generations on C57BL/ 6 background prior to breeding with $S 6 \mathrm{~K}^{-1-}$ mice. Isolated islets were obtained from adult WT $\mathrm{Tg}(R I P-$ $S 6 K 1)$ and $S 6 \mathrm{~K}^{-1-} \mathrm{Tg}(R I P-S 6 K 1)$ mice by collagenase P digestion (14). The lysates were analyzed by Western blotting with antibodies against S6K1 (Santa Cruz Biotechnology Inc.) and c-Myc (Upstate Biotechnology Inc.). Two of $15 S 6 \mathrm{~K}^{-1-} \mathrm{Tg}(\mathrm{RIP}-\mathrm{S} 6 \mathrm{~K} 1)$ mouse lines were positive for S6K1 expression, and one of them could be maintained for experimentation. The hypothalamus was dissected from 3-6 mice per established genotypes to assess S6K1 expression.

Metabolic phenotyping. Indirect calorimetry, locomotor activity, metabolic performance, and home-cage activity were studied by using a combined indirect calorimetry system (TSE Systems GmbH). 
Volumes of oxygen consumed $\left(\mathrm{VO}_{2}, \mathrm{ml} / \mathrm{kg} / \mathrm{h}\right)$ and carbon dioxide produced $\left(\mathrm{VCO}_{2}, \mathrm{ml} / \mathrm{kg} / \mathrm{h}\right)$ were measured continuously and simultaneously every 45 minutes to determine the respiratory quotient (RQ; $\mathrm{VCO}_{2} / \mathrm{VO}_{2}$ ) and to calculate $\mathrm{EE}(\mathrm{kcal} / \mathrm{kg} / \mathrm{h}, \mathrm{EE}=3.815 \times 10-3 \times$ $\mathrm{VO}_{2}+1.232 \times 10-3 \times \mathrm{V} \mathrm{CO}_{2}$ ). During the 95 hours of measurements, the animals remained unconstrained except for a single filling of both water bottles and food hoppers. Prior to the experiment, all mice were allowed to acclimatize to the air-tight cages for 22 hours.

Body composition analysis. Whole-body composition (fat and lean mass) was measured using NMR technology (EchoMRI).

Statistics. Data are presented as mean \pm SEM. The main and interactive effects were analyzed by ANOVA factorial or repeated measurements, or by 1-way ANOVA. Differences between individual group means were analyzed by a post-hoc Bonferroni test or 2-tailed unpaired $t$ test. Analyses were performed using GraphPad Prism software. Differences were considered to be statistically significant at $P<0.05$.

Study approval. Animal care and study protocols were approved by the Institutional Animal Care and Use Committee of Sungkyunkwan University School of Medicine and the Animal care committee of the University of Cincinnati, and were in accordance with NIH guidelines.

\section{Acknowledgments}

We thank S. Pyo (Sungkyunkwan University, Suwon, Kyunggido, South Korea) for help with the embryo growth analysis and apoptosis assay, B. Thorens (University of Lausanne, Lausanne, Switzerland) for anti-Glut2 antibodies, and A. Nagy (LunenfeldTanenbaum Research Institute, Toronto, Ontario, Canada) for fruitful discussions. We are grateful to M. Daston for manuscript editing and G. Doerman for expertise in preparing figures. S.H. Um, G. Thomas, and S.C. Kozma were supported by a Novartis Biomedical Research Institute Funds. S.H. Um is supported by a Korea Healthcare technology R\&D Project grant HI12C0375 in Korea. S.C. Kozma was supported by Juvenile Diabetes Research Foundation grant 1-2009-293; G. Thomas and S.C. Kozma are supported by Instituto de Salud Carlos III (IIS10/00015 and IIS12/00002, respectively). A. Tauler and S.C. Kozma are supported by the Spanish Ministry of Economy and Competitive (BFU2012-38867) grant. G. Thomas is supported by the Spanish Ministry of Science and Innovation (SAF2011-24967) and the CIG European Commission (PCIG10-GA-2011-304160) grants.

Address correspondence to: Sara C. Kozma, Laboratory of Cancer Metabolism, IDIBELL, 08908 Hospitalet de Llobregat, Barcelona, Spain. Phone: 34.93.260.72.80; E-mail: skozma@idibell. cat. Or to: Sung Hee Um, Department of Molecular Cell Biology, Samsung Biomedical Research Institute, Sungkyunkwan University School of Medicine, Suwon, 440-746, Korea. Phone: 82.31.299.6123; E-mail: shum@skku.edu.
1. Weir GC, Bonner-Weir S. Islet $\beta$ cell mass in diabetes and how it relates to function, birth, and death. Ann N Y Acad Sci. 2013;1281:92-105.

2. Danaei G, et al. National, regional, and global trends in fasting plasma glucose and diabetes prevalence since 1980: systematic analysis of health examination surveys and epidemiological studies with 370 country-years and 2.7 million participants. Lancet. 2011;378(9785):31-40.

3. WHO. Global Status Report On Noncommunicable Diseases 2010. Geneva, Switzerland: World Health Organization; 2011.

4. Kahn SE, Cooper ME, Del Prato S. Pathophysiology and treatment of type 2 diabetes: perspectives on the past, present, and future. Lancet. 2014;383(9922):1068-1083.

5. Um SH, D'Alessio D, Thomas G. Nutrient overload, insulin resistance, and ribosomal protein S6 kinase 1, S6K1. Cell Metab. 2006;3(6):393-402.

6. Pearce LR, et al. Characterization of PF-4708671, a novel and highly specific inhibitor of p70 ribosomal S6 kinase (S6K1). Biochem J. 2010;431(2):245-255.

7. Bae EJ, Yang YM, Kim SG. Abrogation of hyperosmotic impairment of insulin signaling by a novel class of 1,2-dithiole-3-thiones through the inhibition of S6K1 activation. Mol Pharmacol. 2008;73(5):1502-1512.

8. Ye P, et al. Potent and selective thiophene ureatemplated inhibitors of S6K. Bioorg Med Chem Lett. 2011;21(2):849-852.

9. $\mathrm{Um} \mathrm{SH}$, et al. Absence of S6K1 protects against ageand diet-induced obesity while enhancing insulin sensitivity. Nature. 2004;431(7005):200-205.

10. Carnevalli LS, et al. S6K1 plays a critical role in early adipocyte differentiation. Dev Cell. 2010;18(5):763-774.
11. Harrington LS, et al. The TSC1-2 tumor suppressor controls insulin-PI3K signaling via regulation of IRS proteins. J Cell Biol. 2004;166(2):213-223.

12. Shah OJ, Hunter T. Turnover of the active fraction of IRS1 involves raptor-mTOR- and S6K1-dependent serine phosphorylation in cell culture models of tuberous sclerosis. Mol Cell Biol. 2006;26(17):6425-6434.

13. Bae EJ, et al. Liver-specific p70 S6 kinase depletion protects against hepatic steatosis and systemic insulin resistance. J Biol Chem. 2012;287(22):18769-18780.

14. Pende M, et al. Hypoinsulinaemia, glucose intolerance and diminished $\beta$ cell size in S6K1-deficient mice. Nature. 2000;408(6815):994-997.

15. Giordano E, Cirulli V, Bosco D, Rouiller D, Halban P, Meda P. B-cell size influences glucose-stimulated insulin secretion. Am J Physiol. 1993;265(2 pt 1):C358-C364.

16. Elghazi L, et al. Decreased IRS signaling impairs beta-cell cycle progression and survival in transgenic mice overexpressing S6K in beta-cells. Diabetes. 2010;59(10):2390-2399.

17. Shima H, Pende M, Chen Y, Fumagalli S, Thomas G Kozma SC. Disruption of the p70s6k/p85s6k gene reveals a small mouse phenotype and a new functional S6 kinase. EMBO J.1998;17(22):6649-6659.

18. Salam RA, Das JK, Bhutta ZA. Impact of intrauterine growth restriction on long-term health. Curr Opin Clin Nutr Metab Care. 2014;17(3):249-254.

19. Romo A, Carceller R, Tobajas J. Intrauterine growth retardation (IUGR): epidemiology and etiology. Pediatr Endocrinol Rev. 2009;6(suppl 3):332-336.

20. Roos S, Lagerlof O, Wennergren M, Powell TL, Jansson T. Regulation of amino acid transporters by glucose and growth factors in cultured primary human trophoblast cells is mediated by mTOR signaling. Am J Physiol Cell Physiol. 2009;297(3):C723-C731.

21. Setia S, Sridhar MG, Bhat V, Chaturvedula L, Vinayagamoorti R, John M. Insulin sensitivity and insulin secretion at birth in intrauterine growth retarded infants. Pathology. 2006;38(3):236-238.

22. Jansson T, Aye IL, Goberdhan DC. The emerging role of mTORC1 signaling in placental nutrientsensing. Placenta. 2012;33(suppl 2):e23-e29.

23. Roos S, Jansson N, Palmberg I, Saljo K, Powell TL, Jansson T. Mammalian target of rapamycin in the human placenta regulates leucine transport and is down-regulated in restricted fetal growth. JPhysiol. 2007;582(pt 1):449-459.

24. McDaniel ML, Marshall CA, Pappan KL, Kwon G. Metabolic and autocrine regulation of the mammalian target of rapamycin by pancreatic beta-cells. Diabetes. 2002;51(10):2877-2885.

25. Limesand SW, et al. Reductions in insulin concentrations and beta-cell mass precede growth restriction in sheep fetuses with placental insufficiency. Am J Physiol Endocrinol Metab. 2013;304(5):E516-E523.

26. Jones RH, Ozanne SE. Fetal programming of glucose-insulin metabolism. Mol Cell Endocrinol. 2009;297(1-2):4-9.

27. Berends LM, Ozanne SE. Early determinants of type-2 diabetes. Best Pract Res Clin Endocrinol Metab. 2012;26(5):569-580.

28. Djouder N, et al. S6K1-mediated disassembly of mitochondrial URI/PP1 $\gamma$ complexes activates a negative feedback program that counters S6K1 survival signaling. Mol Cell. 2007;28(1):28-40.

29. Gonzalez-Rodriguez A, Alba J, Zimmerman V, Kozma SC, Valverde AM. S6K1 deficiency protects against apoptosis in hepatocytes. Hepatol- 
ogy. 2009;50(1):216-229.

30. Montagne J, Stewart MJ, Stocker H, Hafen E, Kozma SC, Thomas G. Drosophila S6 kinase: a regulator of cell size. Science. 1999;285(5436):2126-2129.

31. Rosario FJ, Kanai Y, Powell TL, Jansson T. Mammalian target of rapamycin signalling modulates amino acid uptake by regulating transporter cell surface abundance in primary human trophoblast cells. JPhysiol. 2013;591(pt 3):609-625.

32. Rossant J, Cross JC. Placental development: lessons from mouse mutants. Nat Rev Genet. 2001;2(7):538-548.

33. Barker DJ, Thornburg KL. Placental programming of chronic diseases, cancer and lifespan: a review. Placenta. 2013;34(10):841-845.

34. Forsen T, Eriksson J, Tuomilehto J, Reunanen A, Osmond C, Barker D. The fetal and childhood growth of persons who develop type 2 diabetes. Ann Intern Med. 2000;133(3):176-182.

35. Tanaka M, Hadjantonakis AK, Nagy A. Aggregation chimeras. Combining ES cells, diploid and tetraploid embryos. Methods Mol Biol. 2001;158:135-154.

36. Guillemot F, et al. Genomic imprinting of Mash2, a mouse gene required for trophoblast development. Nat Genet. 1995;9(3):235-242.

37. Eggan K, et al. Hybrid vigor, fetal overgrowth, and viability of mice derived by nuclear cloning and tetraploid embryo complementation. Proc Natl Acad Sci U S A. 2001;98(11):6209-6214.

38. Adams RH, et al. Essential role of $\mathrm{p} 38$ alpha MAP kinase in placental but not embryonic cardiovascular development. Mol Cell. 2000;6(1):109-116.

39. Radimerski T, Montagne J, Hemmings-Mieszczak M, Thomas G. Lethality of Drosophila lacking TSC tumor suppressor function rescued by reducing dS6K signaling. Genes Dev. 2002;16(20):2627-2632.
40. Dowling RJ, et al. mTORC1-mediated cell proliferation, but not cell growth, controlled by the 4E-BPs. Science. 2010;328(5982):1172-1176.

41. Dandoy-Dron F, Itier JM, Monthioux E, Bucchini D, Jami J. Tissue-specific expression of the rat insulin 1 gene in vivo requires both the enhancer and promoter regions. Differentiation. 1995;58(4):291-295.

42. Kubota N, et al. Insulin receptor substrate 2 plays a crucial role in beta cells and the hypothalamus. J Clin Invest. 2004;114(7):917-927.

43. Raoux M, et al. Multilevel control of glucose homeostasis by adenylyl cyclase 8. Diabetologia. 2014;58(4):749-757.

44. Carracedo A, et al. Inhibition of mTORC1 leads to MAPK pathway activation through a PI3Kdependent feedback loop in human cancer. JClin Invest. 2008;118(9):3065-3074.

45. Martin-Pèrez J, Thomas G. Ordered phosphorylation of 40 S ribosomal protein 56 after serum stimulation of quiescent $3 \mathrm{~T} 3$ cells. Proc Natl Acad Sci U S A. 1983;80(4):926-930.

46. Ruvinsky I, et al. Ribosomal protein S6 phosphorylation is a determinant of cell size and glucose homeostasis. Genes Dev. 2005;19(18):2199-2211.

47. Gangloff YG, et al. Disruption of the mouse mTOR gene leads to early postimplantation lethality and prohibits embryonic stem cell development. Mol Cell Biol. 2004;24(21):9508-9516.

48. Pullen N, et al. Phosphorylation and activation of p70s6k by PDK1. Science. 1998;279(5351):707-710.

49. Hashimoto N, et al. Ablation of PDK1 in pancreatic $\beta$ cells induces diabetes as a result of loss of beta cell mass. Nat Genet. 2006;38(5):589-593.

50. Westmoreland JJ, Wang Q, Bouzaffour M, Baker SJ, Sosa-Pineda B. Pdk1 activity controls proliferation, survival, and growth of developing pancreatic cells. Dev Biol. 2009;334(1):285-298.

51. Gu Y, Lindner J, Kumar A, Yuan W, Magnuson MA. Rictor/mTORC2 is essential for maintaining a balance between $\beta$ cell proliferation and cell size. Diabetes. 2011;60(3):827-837.

52. Rachdi L, et al. Disruption of Tsc 2 in pancreatic $\{$ beta $\}$ cells induces $\{$ beta\} cell mass expansion improved glucose tolerance in a TORC1dependent manner. Proc Natl Acad Sci U S A. 2008;105(27):9250-9255.

53. Roux PP, et al. RAS/ERK signaling promotes site-specific ribosomal protein S6 phosphorylation via RSK and stimulates cap-dependent translation. J Biol Chem. 2007;282(19):14056-14064.

54. Kwon G, Marshall CA, Pappan KL, Remedi MS, McDaniel ML. Signaling elements involved in the metabolic regulation of mTOR by nutrients, incretins, and growth factors in islets. Diabetes. 2004;53(suppl 3):S225-S232.

55 . Ueno M, et al. Regulation of insulin signalling by hyperinsulinaemia: role of IRS- $1 / 2$ serine phosphorylation and the mTOR/p70 S6K pathway. Diabetologia. 2005;48(3):506-518.

56. Johnston O, Rose CL, Webster AC, Gill JS. Sirolimus is associated with new-onset diabetes in kidney transplant recipients. J Am Soc Nephrol. 2008;19(7):1411-1418.

57. Barlow AD, Nicholson ML, Herbert TP. Evidence for rapamycin toxicity in pancreatic beta-cells and a review of the underlying molecular mechanisms. Diabetes. 2013;62(8):2674-2682.

58. Lamming DW, et al. Rapamycin-induced insulin resistance is mediated by mTORC2 loss and uncoupled from longevity. Science. 2012;335(6076):1638-1643.

59. Hemberger M, et al. Parp1-deficiency induces differentiation of ES cells into trophoblast derivatives. Dev Biol. 2003;257(2):371-381.

60. Nagy A, Gertsenstein M, Vintersten K, Behringer R. Manipulating the Mouse Embryo: A Laboratory Manual. Cold Spring Harbor, New York, USA: Cold Spring Harbor Laboratory Press; 2002. 